\title{
Exploring the Fourth Dimension: The Role of Ancient Texts and Herbals for the Identification of Unknown Medicinal Plants
}

\section{Antonino Pollio*}

Department of Biological Sciences, University “Federico II", 80139 Naples, Italy

The identification of local and traditional uses of medicinal plants is the core of ethno-pharmacological research. Field studies should be carried out following three steps: 1). Developing a conceptual framework and hypothesis testing, 2). Establishing minimal methodological standards; 3 ). Suggesting how the gathered information could be used in experimental research and for applied projects [1]. Field studies are presently concentrated in tropical countries of Africa, America and Asia, and in Mediterranean Region, where a large bank of historical texts on herbal remedies, is also available, in some cases dating back to Greek and Roman medicine. The approach to the study of these kinds of information is completely different by those adopted for field studies. The studies on ancient texts should be carried out by an interdisciplinary team composed by members of humanistic and scientific disciplines [2], and some important indications on the methodological approach to this kind of studies have been proposed [3]. The critical point lies on the correct botanical identification of the plants cited in the texts. Chinese, Indian, Arabic and Islamic traditional Medicine also rely on a corpus of ancient knowledge, often available from written sources, but frequently the liaison with the ancient medical tradition has been never interrupted. A large number of people of these countries, particularly in rural settlements, still depend on the same herbal remedies used thousand years ago. In this case, it is possible to identify the plant used in the recipes with a relatively high degree of certainty. In Mediterranean, particularly in the European Countries of Region, as well as in Central and Northern Europe, such practices have been almost completely abandoned. The absence of continuity makes more difficult the botanical identification of the plant cited in old medicinal texts, as well as the comprehension of the anthropological context supporting the therapeutic approach to a disease. Only when a detailed description is available, the best if it is accompanied by a good iconography, it is possible to supply a highly reliable botanical identification, but this is very unusual, mainly in the case of ancient texts written many centuries ago. As early stated for the semantics of Greek names of plants "In the modern [Greek] language the same name is often used for different plants and the same plants sometimes has different names in different part of the country. Nor can we doubt that this was also in Ancient Greece" [4]. Generally, it could be advisable to introduce a degree of certainty of identification of a species, indicating also a list of more than one potential candidate to the correct identification. Notwithstanding these limitations, the study of European material medical in historical texts could give very promising results. In a recent, very detailed study it has been reported that the Mediterranean/European medicine has been based on the Dioscoridean tradition (I century of CE), until the $19^{\text {th }}$ century. From that time on, traditional medicine was considered superseded in Western Countries, but many of the simple used for thousand years could represent an important source for pharmaceutical research [5].

Diachronic research in ethno-pharmacology can also give consistent results when the time span of the research is shorter. A recent successful trend is to concentrate the efforts on the last two centuries, by comparing ethno-pharmacological data from local archives or herbals, sometime containing also voucher specimens, classified according to the standard botanical nomenclature of the time. In this case, even though the information was prevalently collected not by botanists, but amateurs, ethnologists, or physicians, the identification of the species can be verified and updated. Herbals collected in restricted geographical areas can represent an unexplored treasure on traditional herbal medicine of European and Mediterranean region. For example, the analysis conducted by comparing data from four different archives compiled in Poland during the last two centuries revealed that in $19^{\text {th }}$ Century more than 50 wild green vegetables, many of them with a reputation of "food medicine", were commonly used in the Polish diet, while today none of them is commonly eaten [6]. On the contrary, a recent study conducted on the ethno-pharmacological exhibits gathered in Tripolitania, Libya, by the botanist A. Trotter at the beginning of XX century (1912), has shown that almost all of the plants collected are still used in the folk medicine of at least one of the North African Countries, and therapeutic uses of each plant appear consistent over that time [7] The results of these studies seem to suggest that it is possible to collect sensible information from historical text and collections that could open new avenues of experimental research on medicinal plants which since now have received limited consideration.

\section{References}

1. Heinrich M, Edwards S, Moerman DE, Leonti M (2009) Ethnopharmacological field studies: a critical assessment of their conceptual basis and methods. J Ethnopharmacol 124: 1-17

2. Holland BK (1994) Prospecting for drugs in ancient texts. Nature 369: 702

3. Buenz EJ, Schnepple DJ, Bauer BA, Elkin PL, Riddle JM, et al.( 2004) Techniques: Bioprospecting historical herbal texts by hunting for new leads in old tomes Trends Pharmacol Sci 25: 494-498.

4. Dawkins RM (1936) The semantics of Greek names for plants. JHS 56: 1-11.

5. De Vos $P$ (2010) European materia medica in historical texts: longevity of a tradition and implications for future use. J Ethnopharmacol 132: 28-47.

6. Luczaj $L$ (2010) Changes in the utilization of wild green vegetables in Poland since the 19th century: a comparison of four ethnobotanical surveys. Ethnopharmacol 128: 395-404

7. De Natale A, Pollio A (2012) A forgotten collection: the Libyan ethnobotanica exhibits (1912-14) by A. Trotter at the Museum O. Comes at the University Federico II in Naples, Italy. J Ethnobiol Ethnomed 8: 4.

${ }^{*}$ Corresponding author: Antonino Pollio, Department of Biological Sciences, University “Federico II”, 80139 Naples, Italy, Tel: 390812538537; Fax: 390812538523 ; E-mail: anpollio@unina.it

Received August 30, 2011; Accepted September 01, 2012; Published Septembe 07, 2012

Citation: Pollio A (2012) Exploring the Fourth Dimension: The Role of Ancient Texts and Herbals for the Identification of Unknown Medicinal Plants Med Aromat Plants 1:e130. doi:10.4172/2167-0412.1000e130

Copyright: (c) 2012 Pollio A. This is an open-access article distributed under the terms of the Creative Commons Attribution License, which permits unrestricted use, distribution, and reproduction in any medium, provided the original author and source are credited. 